Seismic Data for Evaluation of Ground Motion Hazards in Las Vegas in Support of Test Site Readiness Ground Motion

A. Rodgers

January 18,2008 
This document was prepared as an account of work sponsored by an agency of the United States government. Neither the United States government nor Lawrence Livermore National Security, LLC, nor any of their employees makes any warranty, expressed or implied, or assumes any legal liability or responsibility for the accuracy, completeness, or usefulness of any information, apparatus, product, or process disclosed, or represents that its use would not infringe privately owned rights. Reference herein to any specific commercial product, process, or service by trade name, trademark, manufacturer, or otherwise does not necessarily constitute or imply its endorsement, recommendation, or favoring by the United States government or Lawrence Livermore National Security, LLC. The views and opinions of authors expressed herein do not necessarily state or reflect those of the United States government or Lawrence Livermore National Security, LLC, and shall not be used for advertising or product endorsement purposes.

This work performed under the auspices of the U.S. Department of Energy by Lawrence Livermore National Laboratory under Contract DE-AC52-07NA27344. 


\title{
Seismic Data for Evaluation of Ground Motion Hazards in Las Vegas in Support of Test Site Readiness Ground Motion
}

\author{
Arthur Rodgers \\ Atmospheric, Earth and Energy Division \\ Chemistry, Materials, Earth and Life Sciences Directorate \\ Science and Technology Principle Directorate \\ Lawrence Livermore National Laboratory \\ Livermore, CA 94551 \\ Email: rodgers7@1lnl.gov; Phone: (925) 423-5018; Fax: (925) 423-4077
}

\section{Summary}

In this report we describe the data sets used to evaluate ground motion hazards in Las Vegas from nuclear tests at the Nevada Test Site. This analysis is presented in Rodgers et al. $(2005,2006)$ and includes 13 nuclear explosions recorded at the John Blume and Associates network, the Little Skull Mountain earthquake and a temporary deployment of broadband station in Las Vegas. The data are available in SAC format on CD-ROM as an appendix to this report.

\section{Historical Explosion Data}

The engineering firm Blume and Associates operated the Seismic Safety Program to measure ground motion throughout the western U.S. from nuclear explosions at NTS. A seismic station network was installed in the early 1960's and operated until the end of nuclear testing in 1992. Data were used to understand the response of Las Vegas Basin to ground motion from nuclear explosions at NTS and the impact on buildings and structures. The network configuration and instrumentation varied through time. We obtained data recorded on three component analog strong motion accelerographs. The ground motions were digitized at 200 samples per second. We found these records to be useful in the pass band $0.2-5 \mathrm{~Hz}$ (details provide below). The instrument corrected 
ground motion time series from legacy NTS shots were read from their archival ASCII format and converted to Seismic Analysis Code (SAC2000) format (Goldstein et al., 2003). We did not have absolute time information for the seismograms, so we could not analyze travel times or surface wave dispersion.

All seismograms for NTS explosions recorded in LVV were previewed and P- and Swaves were picked. We collected records for thirteen nuclear test explosions recorded at 29 sites in LVV, however only four explosions (BARNWELL, BODIE, COTTAGE and GASCON) were recorded at our best hard rock reference site, SGS located on the flank of Frenchman Mountain. Table 2.1 compiles details about the nuclear explosions taken from Springer et al. (2002). None of the explosions we collected were included in the analysis of Murphy and Hewlett (1975).

Table 1. Event information for the NTS nuclear explosions (Springer et al., 2002) and earthquakes used in this study. Body-wave magnitudes, $\mathrm{m}_{\mathrm{b}}$, are taken from the International Seismological Centre (ISC) catalog.

\begin{tabular}{|l|l|l|l|l|l|l|l|l|}
\hline Name & Date & $\begin{array}{l}\text { Time } \\
\text { (UTC) }\end{array}$ & Region & Latitude & Longitude & $\begin{array}{l}\text { Depth } \\
\text { (meters) }\end{array}$ & $\begin{array}{l}\mathbf{m}_{\mathbf{b}} \\
\text { Yield } \\
\text { (kiloton) }\end{array}$ \\
\hline BOXCAR & 1968 Apr 26 & $15: 00: 00.07$ & Pahute & 37.295 & -116.457 & 1158 & - & 1300 \\
\hline HANDLEY & 1970 Mar 26 & $19: 00: 00.20$ & Pahute & 37.300 & -116.535 & 1209 & - & $>1000$ \\
\hline MUENSTER & 1976 Jan 03 & $19: 15: 00.16$ & Pahute & 37.297 & -116.334 & 1452 & - & $200-1000$ \\
\hline FONTINA & 1976 Feb 12 & $14: 45: 00.16$ & Pahute & 37.271 & -116.489 & 1219 & - & $200-1000$ \\
\hline JORNADA & 1982 Jan 28 & $16: 00: 00.10$ & Yucca & 37.091 & -116.052 & 639 & 5.9 & 139 \\
\hline NEBBIOLO & 1982 Jun 24 & $14: 15: 00.09$ & Pahute & 37.236 & -116.371 & 640 & 5.6 & $20-150$ \\
\hline TURQUOISE & 1983 Apr 14 & $19: 05: 00.12$ & Yucca & 37.073 & -116.047 & 533 & 5.7 & $<150$ \\
\hline MUNDO & 1984 May 01 & $19: 05: 00.09$ & Yucca & 37.106 & -116.023 & 566 & 5.3 & $20-150$ \\
\hline COTTAGE* & 1985 Mar 23 & $18: 30: 00.08$ & Yucca & 37.180 & -116.090 & 515 & 5.3 & $20-150$ \\
\hline GASCON* & 1986 Nov 14 & $16: 00: 00.07$ & Yucca & 37.100 & -116.049 & 593 & 5.8 & $20-150$ \\
\hline BODIE* & 1986 Dec 13 & $17: 50: 05.08$ & Pahute & 37.263 & -116.413 & 635 & 5.5 & $20-150$ \\
\hline TAHOKA & 1987 Aug 13 & $14: 00: 00.09$ & Yucca & 37.061 & -116.046 & 639 & 5.9 & $20-150$ \\
\hline BARNWELL* & 1989 Dec 08 & $15: 00: 00.09$ & Pahute & 37.231 & -116.410 & 601 & 5.5 & $20-150$ \\
\hline & & & & & & & & \\
\hline LSM* & 1992 Jun 29 & $10: 14: 00.00$ & LSM & 36.72 & -116.30 & 11,000 & 5.4 & - \\
\hline LVVBB1* & 2002 Sep 28 & $10: 34: 46.00$ & Coso & 35.95 & -117.31 & 15,000 & 4.1 & - \\
\hline LVVBB2* & 2002 Nov 25 & $00: 03: 10.05$ & Goldfield & 37.38 & -117.19 & 7,000 & 3.9 & - \\
\hline
\end{tabular}

* indicates events recorded at reference site SGS/ST17 
Explosion events were located in the Pahute Mesa and Yucca Flat areas of NTS. Both source regions have very similar paths from NTS to LVV, however the emplacement geologies are very different leading to differences in S-wave generation at the source (Mayeda and Walter, 1996). The events tend to have large teleseismic body-wave magnitudes, $m_{b}$, between 5.3 and 5.9. Figure 1 shows a map of the Blume and Associates sites in LVV that recorded at least one explosion. The explosion locations on the NTS are shown in Figure 2.

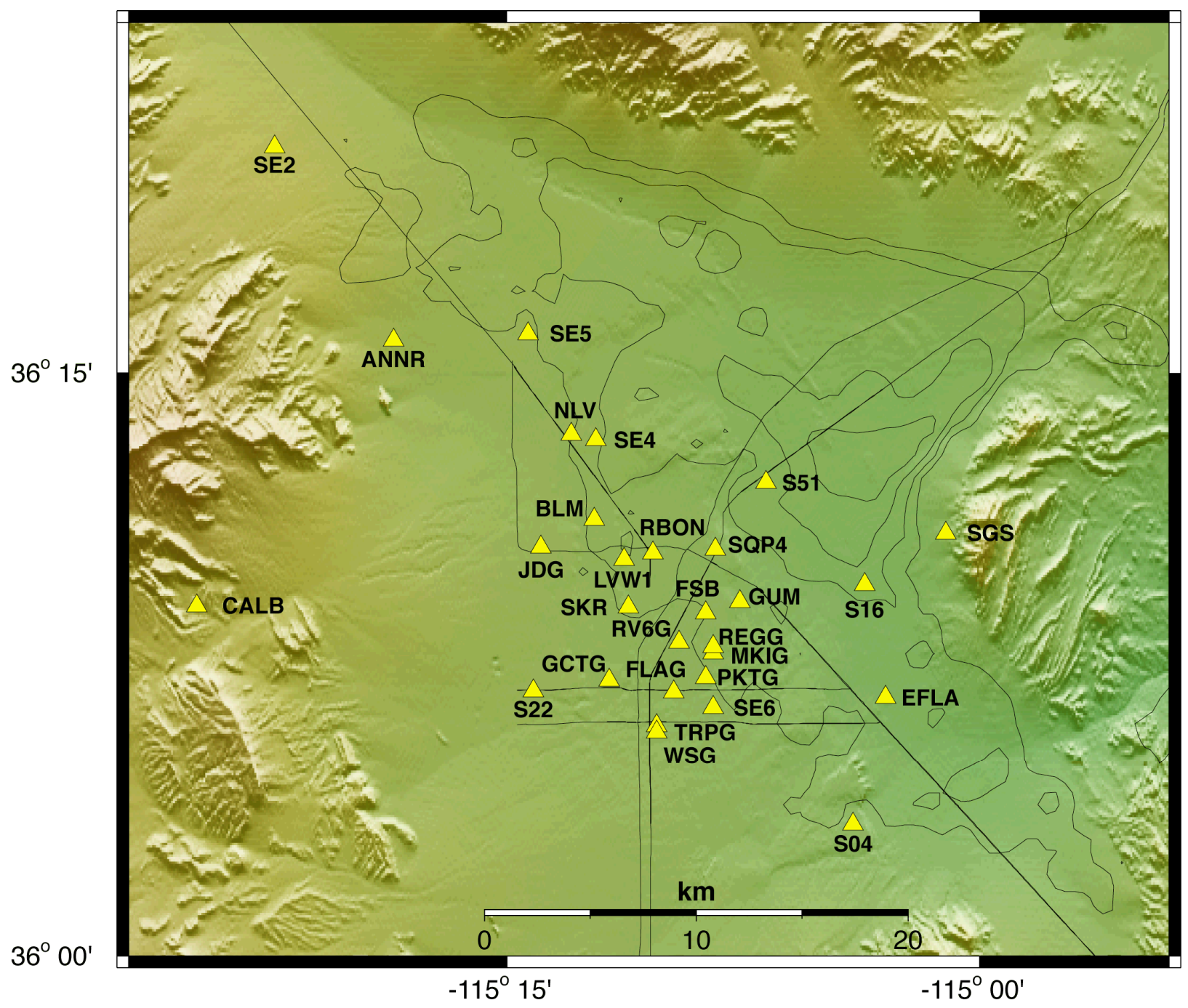

Figure 1. Seismic stations from the BLUME network that recorded the historical nuclear explosions at NTS (yellow triangles). Basin depths from Langenheim et al. (2001) are shown as black contour lines (contour interval $1 \mathrm{~km}$ ). 


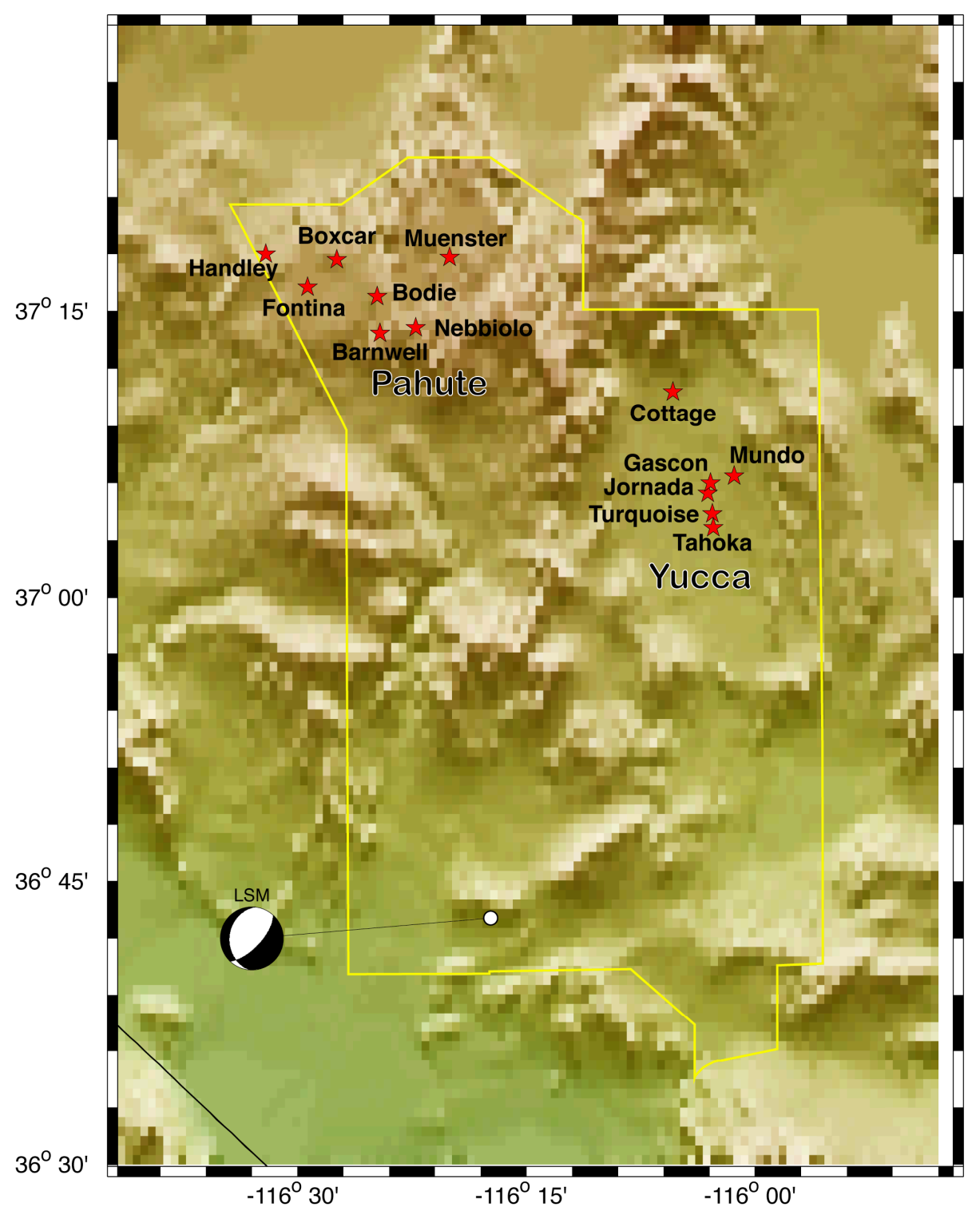

Figure 2. Map of nuclear explosions recorded by the BLUME network. The June 29, 1992 Little Skull Mountain earthquake on NTS is also shown.

\section{Little Skull Mountain Earthquake}

We also obtained data for the 29 June 1992 Little Skull Mountain earthquake on NTS recorded by the Blume \& Associates network and analyzed by Su et al. (1998). These sites (LSM) are shown in Figure 3. Station ST17 was essentially co-located with the BLUME station SGS. 


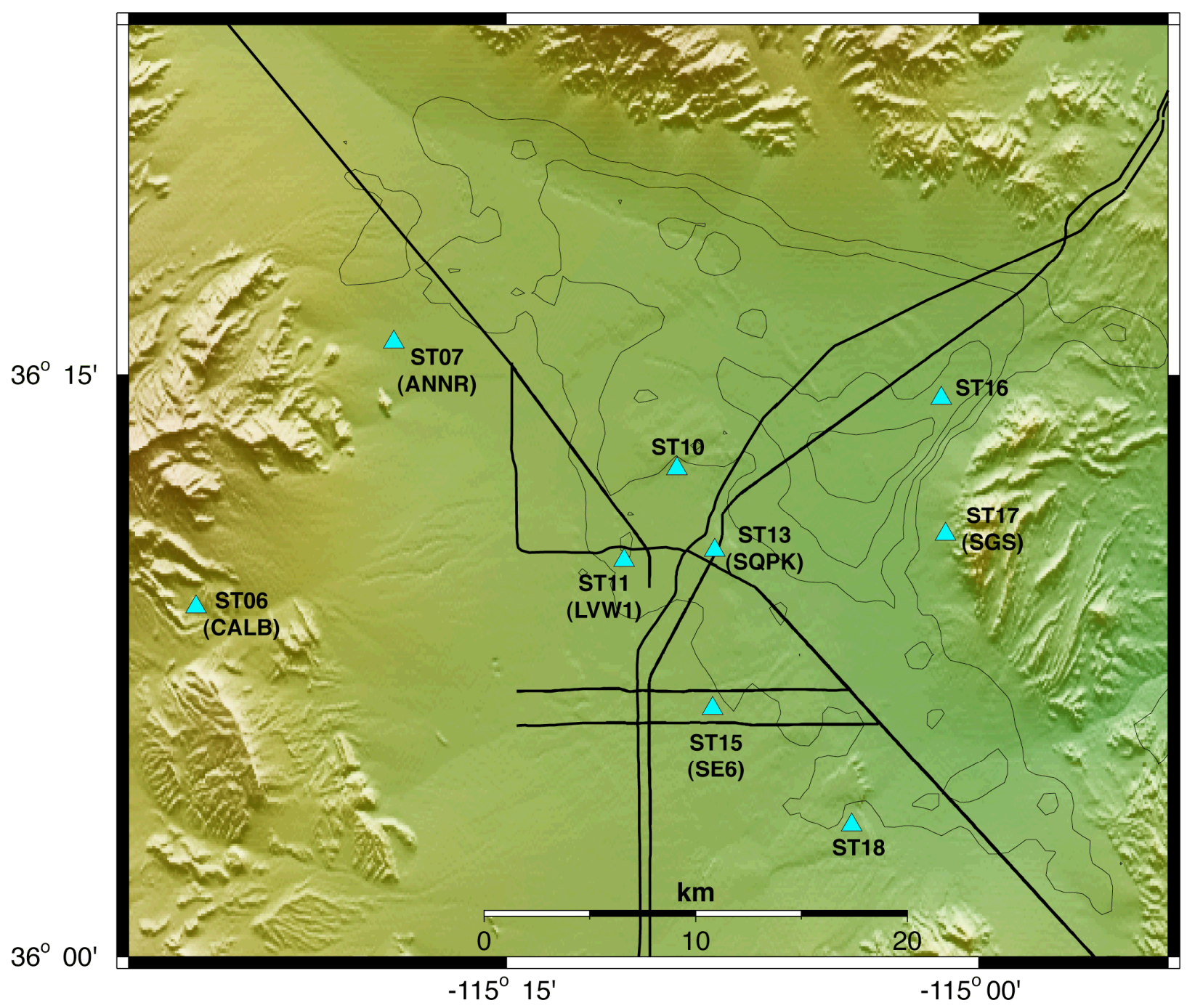

Figure 3. Seismic stations from the BLUME network that recorded the Little Skull Mountain earthquake (cyan triangles). Basin depths from Langenheim et al. (2001) are shown as in Figure 1.

\section{Las Vegas Broadband Deployment}

The available sites from the BLUME and LSM networks sample the densely populated central portion of LVV, but not the northern portion of the valley. Thicker sedimentary cover underlies the northern portion of the valley (Langenheim et al., 2001a). In order to improve the spatial coverage of LVV with seismic sensors, and investigate the response of the deeper sediments in the northern valley, we deployed a temporary network of seismometers. The Las Vegas Valley Broadband Deployment (LVVBB) recorded 
continuous weak motions from local, regional and teleseismic events between September 2002 and January 2003. The eleven stations, shown in Figure 4, were configured to sample the northern parts of LVV along densely populated the Las Vegas Boulevard/I-15 corridor as well as to overlap sites from the BLUME and LSM data sets.

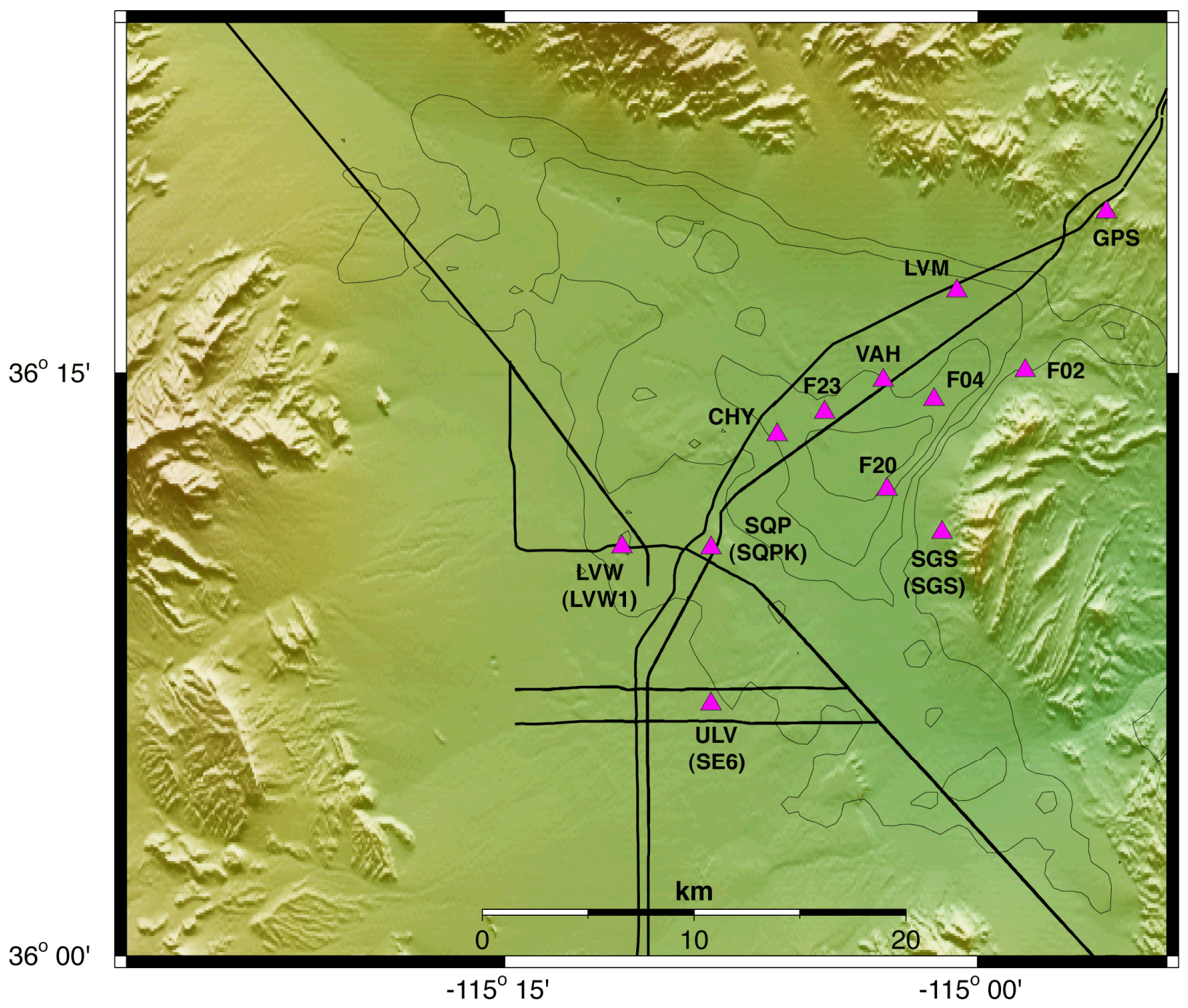

Figure 4. Seismic stations from the Las Vegas Valley Broadband Deployment network (magenta triangles). Basin depths from Langenheim et al. (2001) are shown as in Figure 1.

We deployed one station on the foot of Frenchman Mountain near the BLUME station SGS, although the area near SGS has been urbanized since the time of the BLUME network. The LVVBB stations featured various instruments including Guralp CMG3ESP, Guralp 40T and Geotech S-13 sensors. Reftek 72A-08 24-bit data loggers 
recorded data with GPS time at 40 samples per second. Two regional earthquakes were used for site response measurements (Table 1).

\section{NTS Explosions at the BLUME Sites}

Our analysis of ground motions in LVV (Rodgers et al., 2006) relied heavily on the historical recordings of NTS nuclear explosions recorded by the Blume and Associates network. In this section we provide some details about the data. Some events were recorded by only a few sites in Las Vegas. This can be seen in Figures 5-17, which show the specific sites that recorded each of the 13 explosions along with the entire Blume, LSM and LVVBB networks. Because the sampling of the explosions in Las Vegas was so geographically heterogeneous, a major objective of our project was to obtain sampling of the amplifications in the northern parts of Las Vegas, for which we have no explosion recordings.

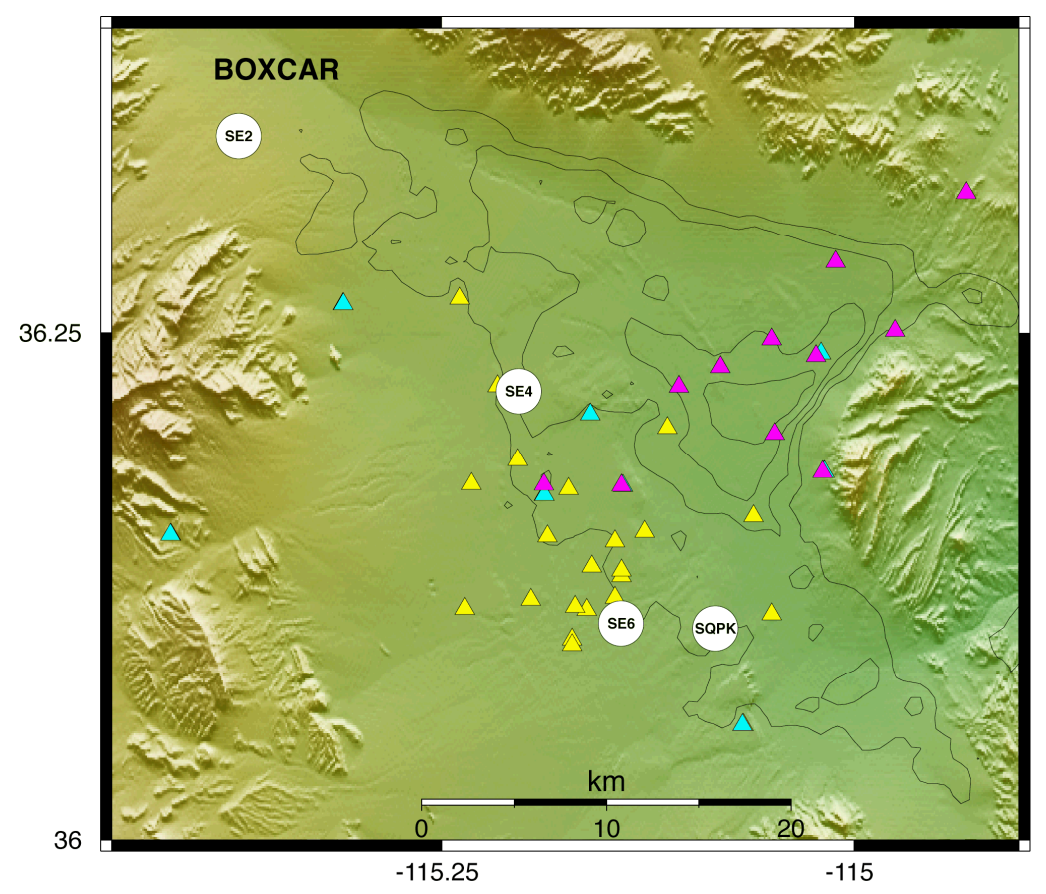

Figure 5. BLUME network stations (circles) in Las Vegas with good recordings of the BOXCAR explosion. Stations from the BLUME, LSM and LVVBB data sets and basin depths from Langenheim et al. (2001) are shown as in Figure 1. 


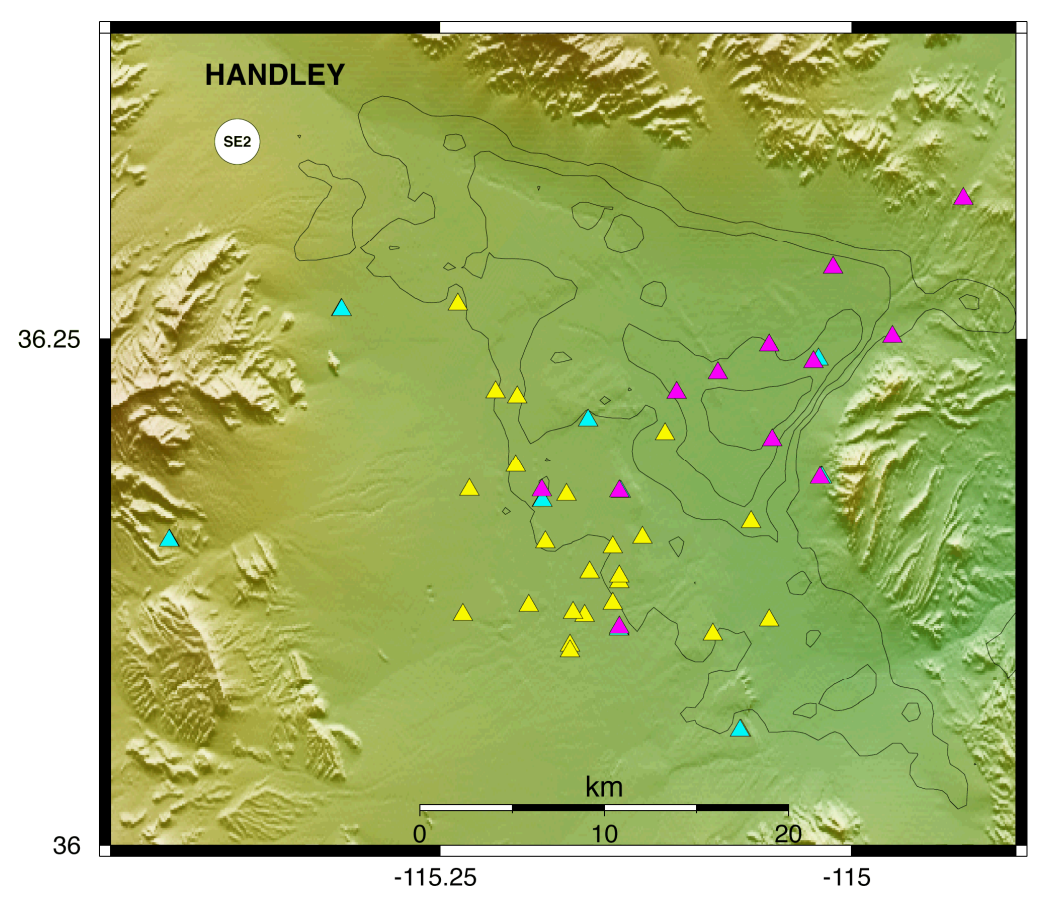

Figure 6. BLUME network stations (circles) in Las Vegas with good recordings of the HANDLEY explosion. Stations from the BLUME, LSM and LVVBB data sets and basin depths from Langenheim et al. (2001) are shown as in Figure 1.

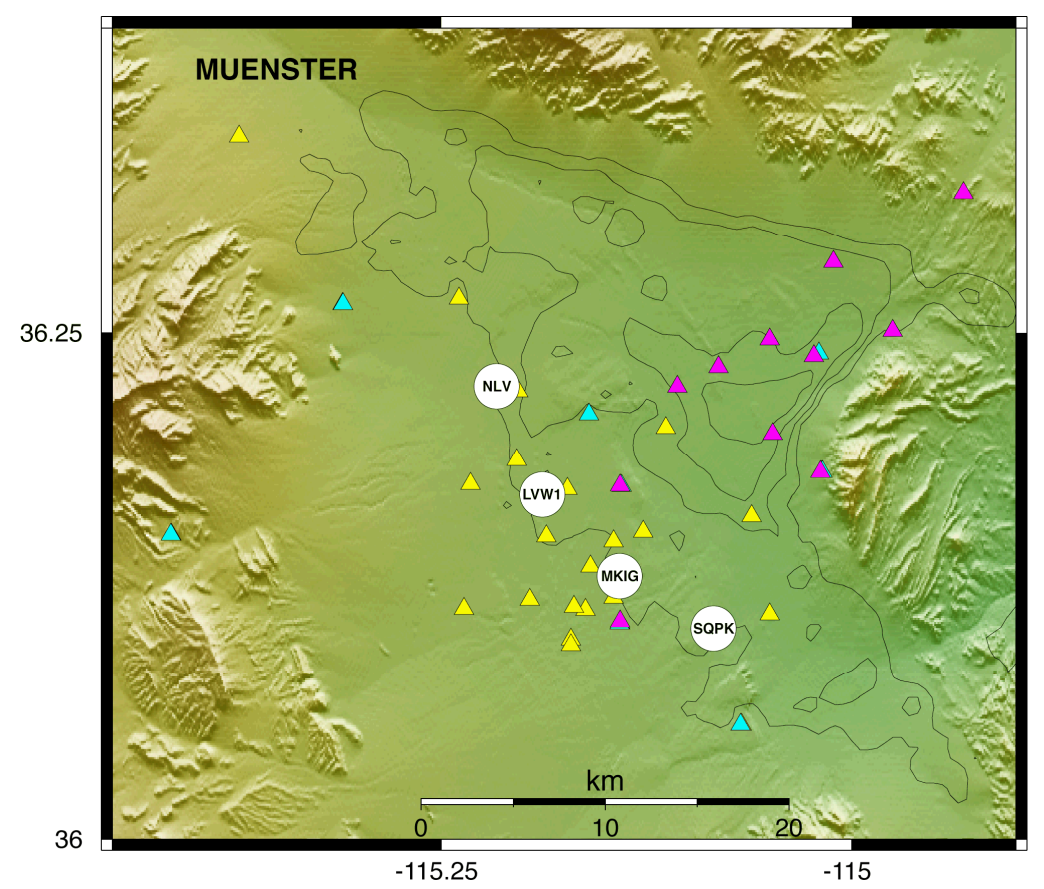

Figure 7. BLUME network stations (circles) in Las Vegas with good recordings of the MUENSTER explosion. Stations from the BLUME, LSM and LVVBB data sets and basin depths from Langenheim et al. (2000) are shown as in Figure 1. 


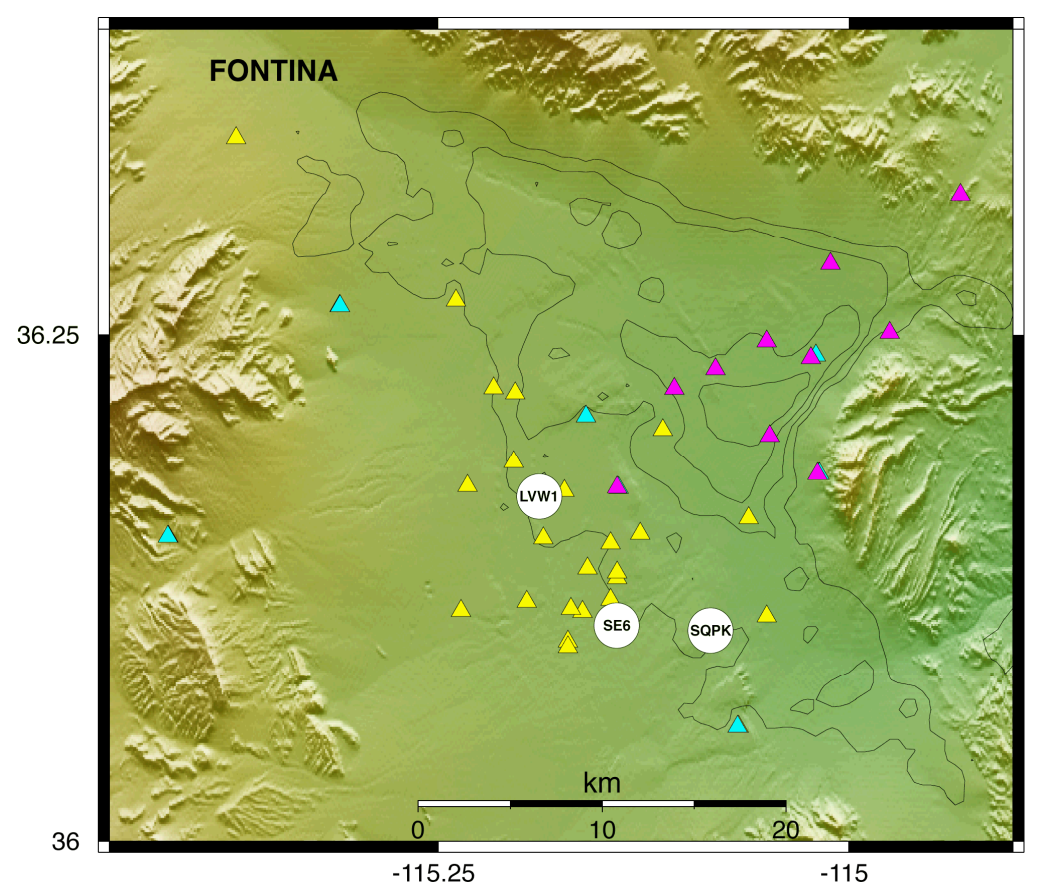

Figure 8. BLUME network stations (circles) in Las Vegas with good recordings of the FONTINA explosion. Stations from the BLUME, LSM and LVVBB data sets and basin depths from Langenheim et al. (2001) are shown as in Figure 1.

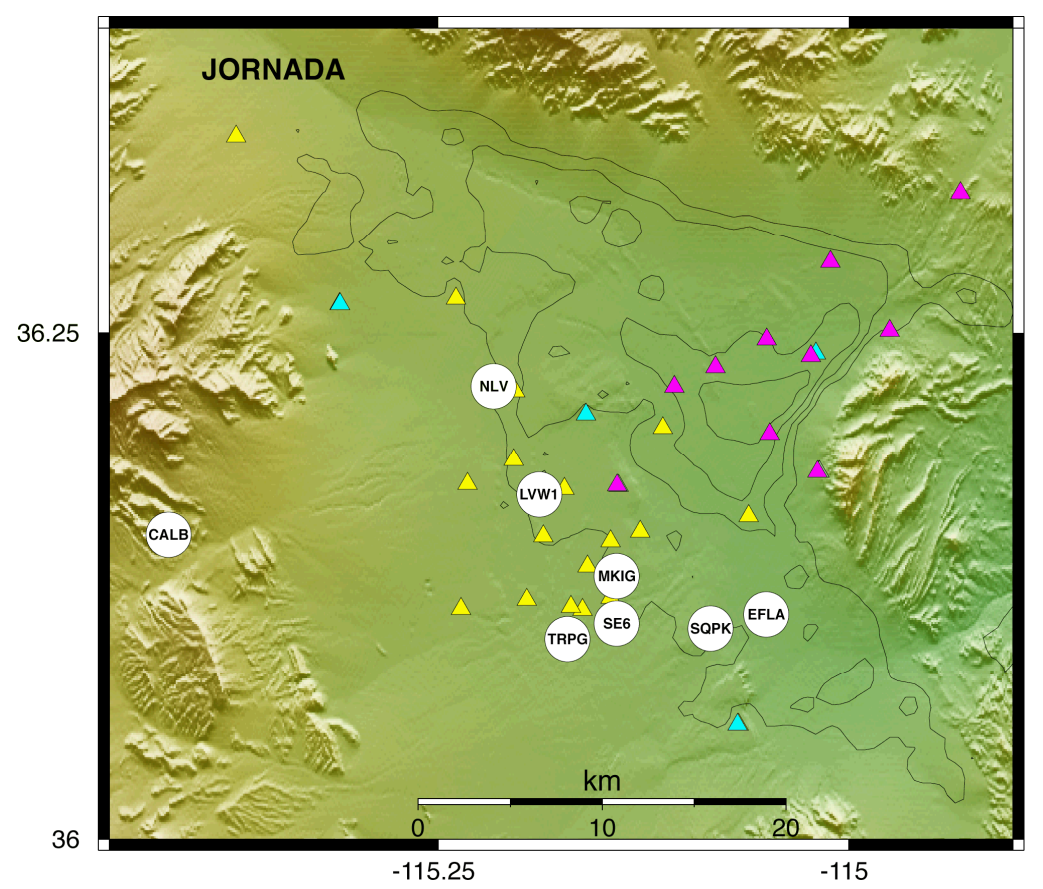

Figure 9. BLUME network stations (circles) in Las Vegas with good recordings of the JORNADA explosion. Stations from the BLUME, LSM and LVVBB data sets and basin depths from Langenheim et al. (2001) are shown as in Figure 1. 


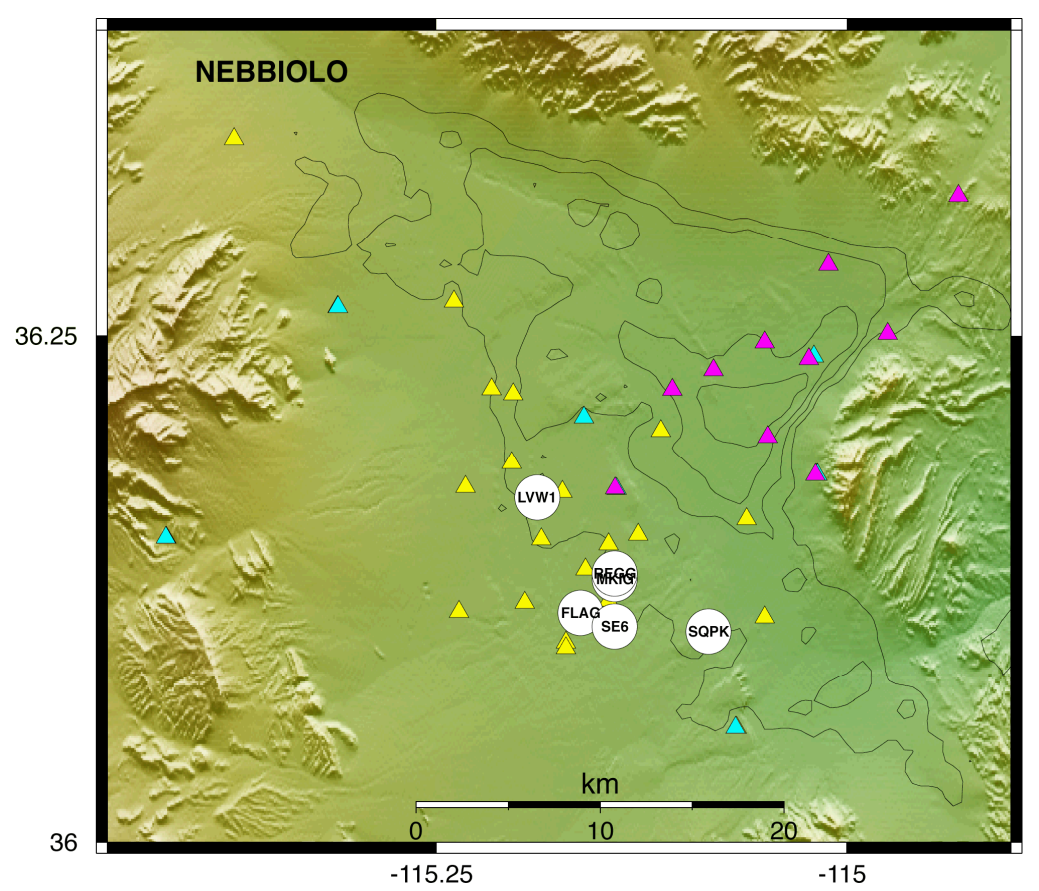

Figure 10. BLUME network stations (circles) in Las Vegas with good recordings of the NEBBIOLO explosion. Stations from the BLUME, LSM and LVVBB data sets and basin depths from Langenheim et al. (2001) are shown as in Figure 1.

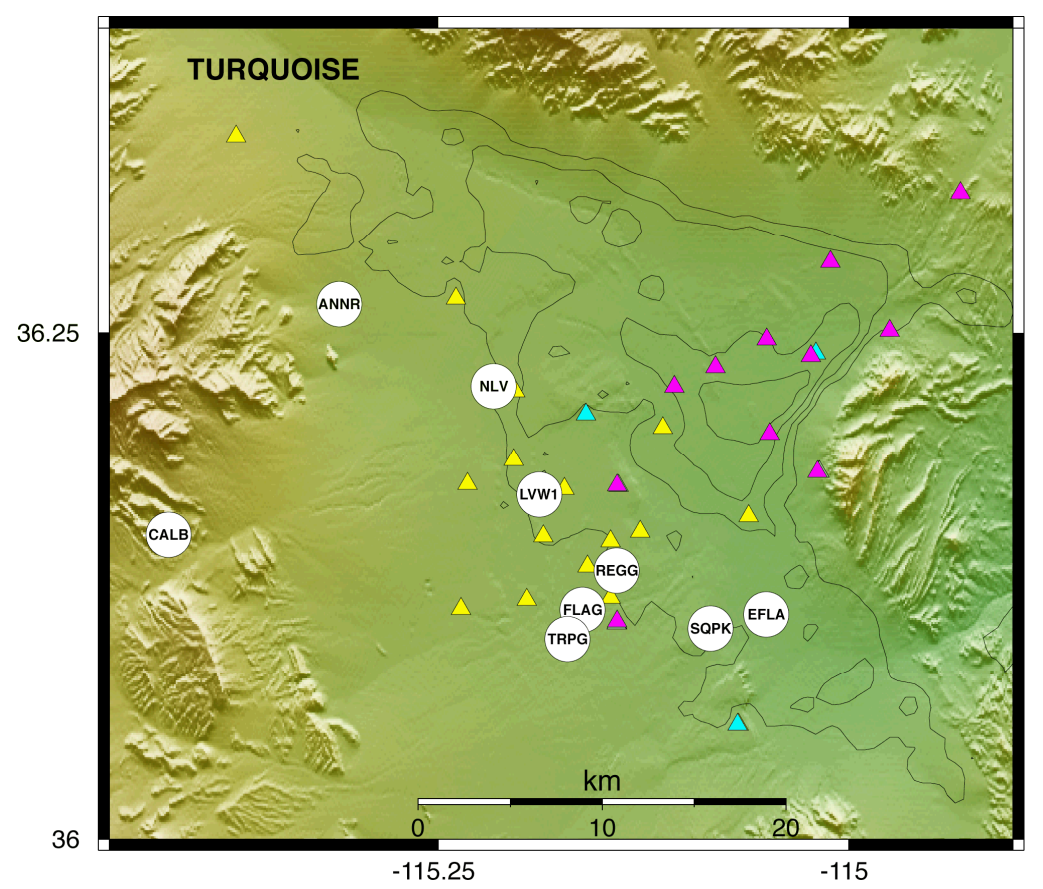

Figure 11. BLUME network stations (circles) in Las Vegas with good recordings of the TURQUOISE explosion. Stations from the BLUME, LSM and LVVBB data sets and basin depths from Langenheim et al. (2001) are shown as in Figure 1. 


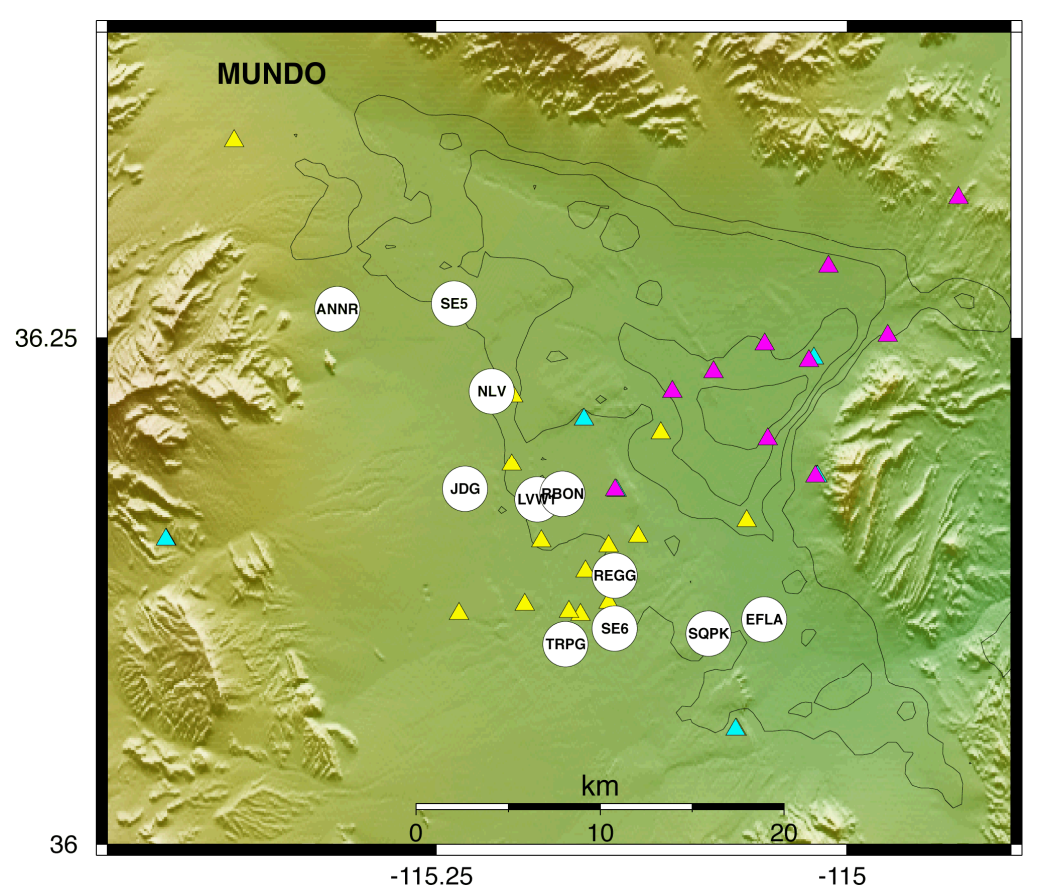

Figure 12. BLUME network stations (circles) in Las Vegas with good recordings of the MUNDO explosion. Stations from the BLUME, LSM and LVVBB data sets and basin depths from Langenheim et al. (2001) are shown as in Figure 1.

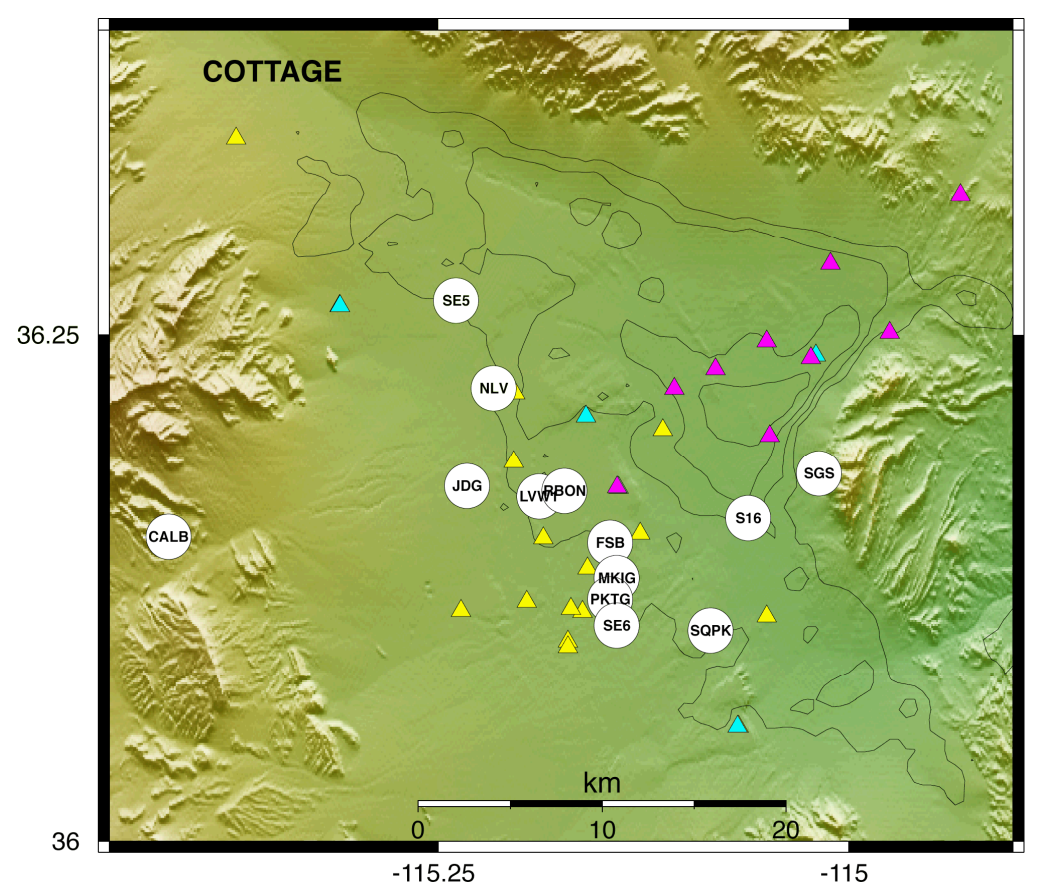

Figure 13. BLUME network stations (circles) in Las Vegas with good recordings of the COTTAGE explosion. Stations from the BLUME, LSM and LVVBB data sets and basin depths from Langenheim et al. (2001) are shown as in Figure 1. 


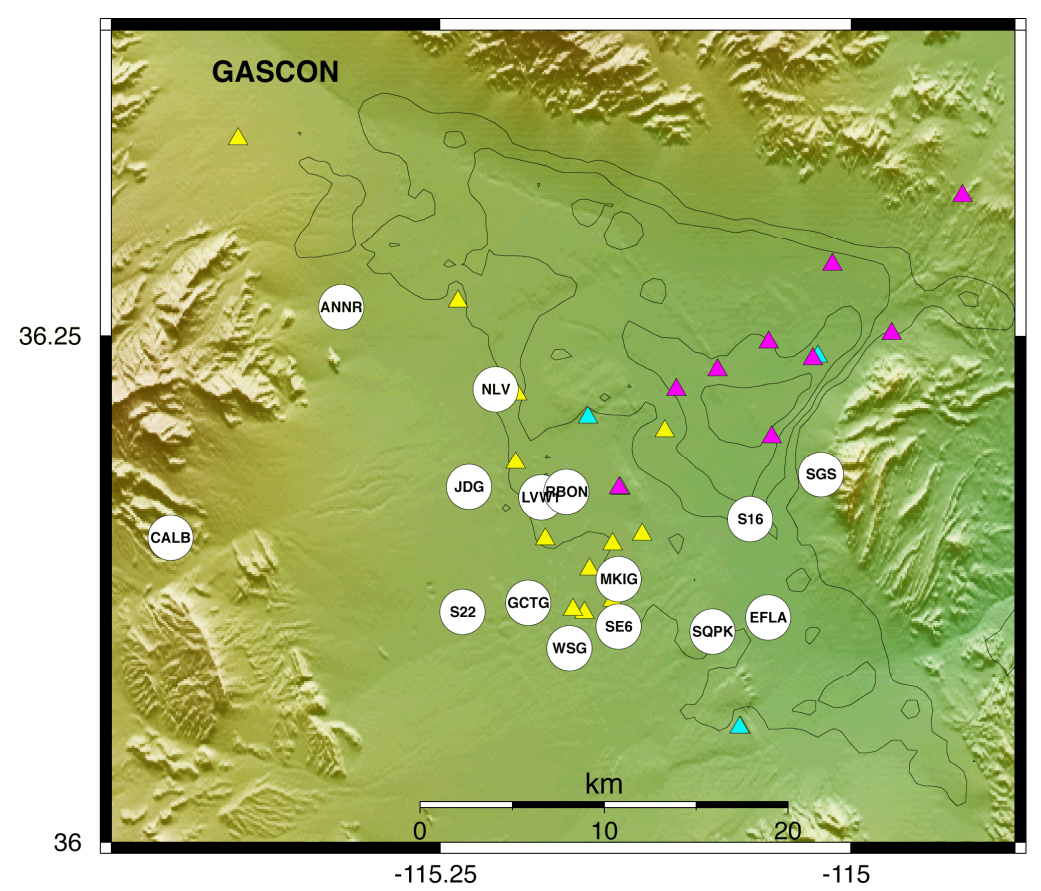

Figure 14. BLUME network stations (circles) in Las Vegas with good recordings of the GASCON explosion. Stations from the BLUME, LSM and LVVBB data sets and basin depths from Langenheim et al. (2001) are shown as in Figure 1.

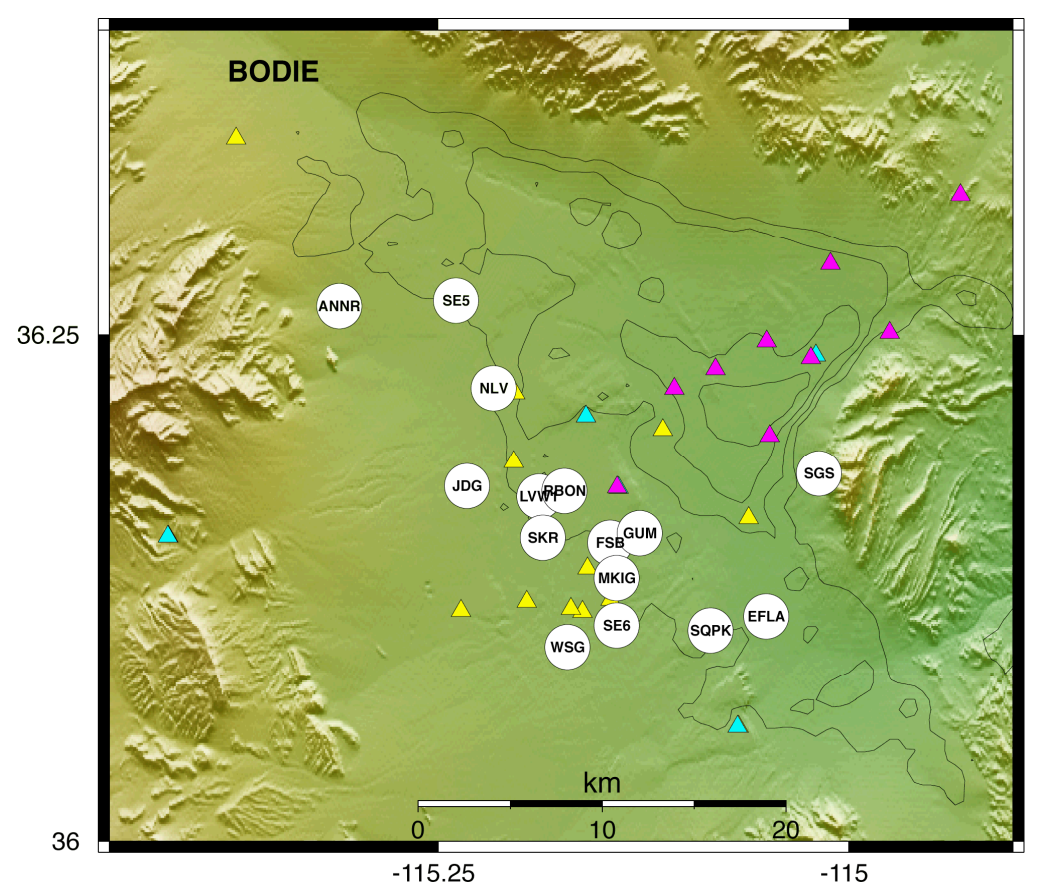

Figure 15. BLUME network stations (circles) in Las Vegas with good recordings of the BODIE explosion. Stations from the BLUME, LSM and LVVBB data sets and basin depths from Langenheim et al. (2001) are shown as in Figure 1. 


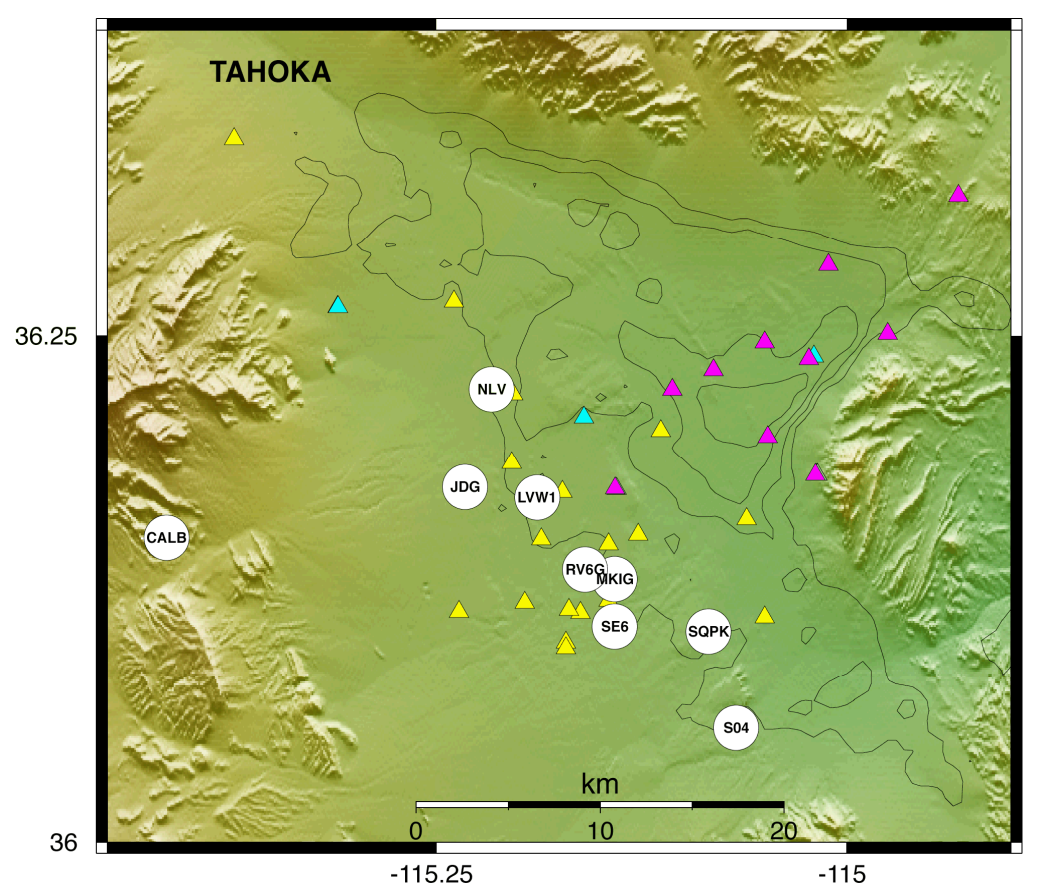

Figure 16. BLUME network stations (circles) in Las Vegas with good recordings of the TAHOKA explosion. Stations from the BLUME, LSM and LVVBB data sets and basin depths from Langenheim et al. (2001) are shown as in Figure 1.

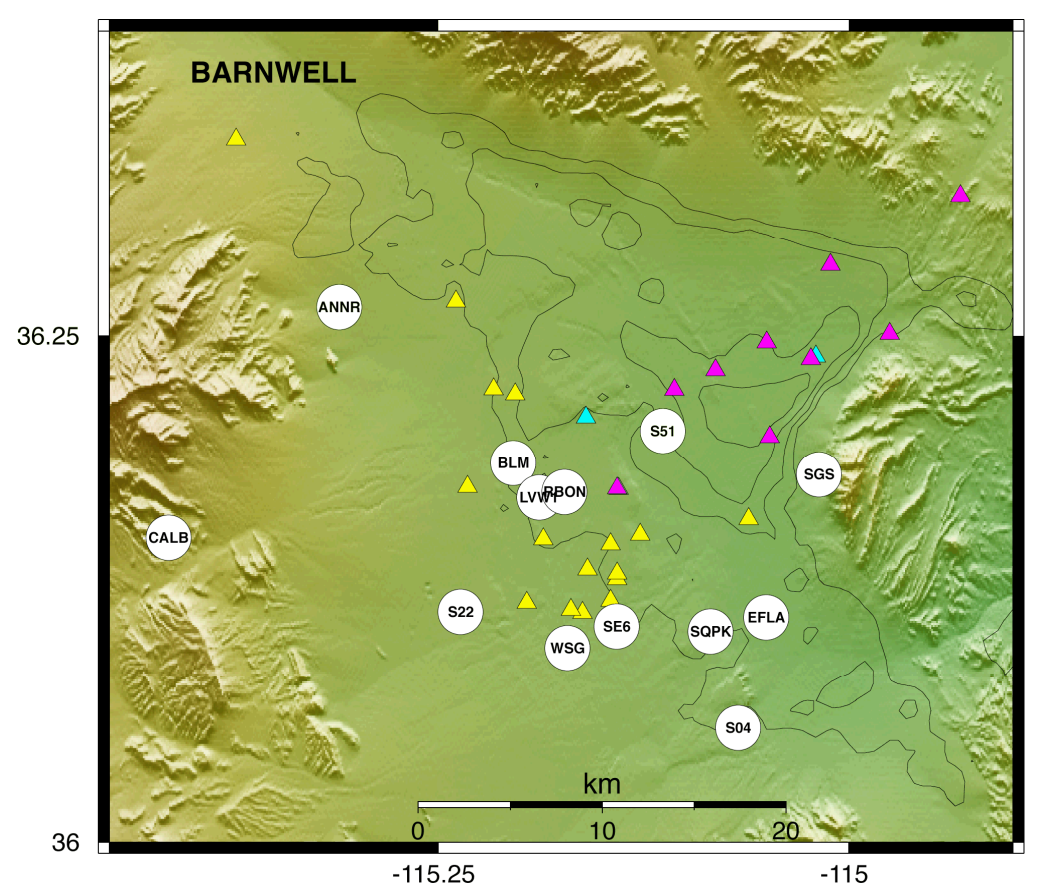

Figure 17. BLUME network stations (circles) in Las Vegas with good recordings of the BARNWELL explosion. Stations from the BLUME, LSM and LVVBB data sets and basin depths from Langenheim et al. (2001) are shown as in Figure 1. 
As an example of the BLUME data set, we show (Figure 18) the north component velocity seismograms (band pass filtered $0.1-10 \mathrm{~Hz}$ ) for the BARNWELL shot at six sites throughout the Valley (station locations are shown in Figure 17). Amplitudes at the sites SGS and CALB, on the Valley's periphery, are the smallest, while amplitudes within the basin are largest, particularly at RBON, LVW and S51. Note that the duration of elevated ground motion is quite long within the basin and the slower surface waves and coda tend to be longer period than the direct S-wave. The long duration and amplified ground motions are common within sedimentary basins. Note that accelerations from the nuclear explosion data considered were always below $20 \mathrm{~cm} / \mathrm{s}^{2}(\sim 2 \% \mathrm{~g})$ and would generally be considered weak motion and unlikely to cause serious damage.
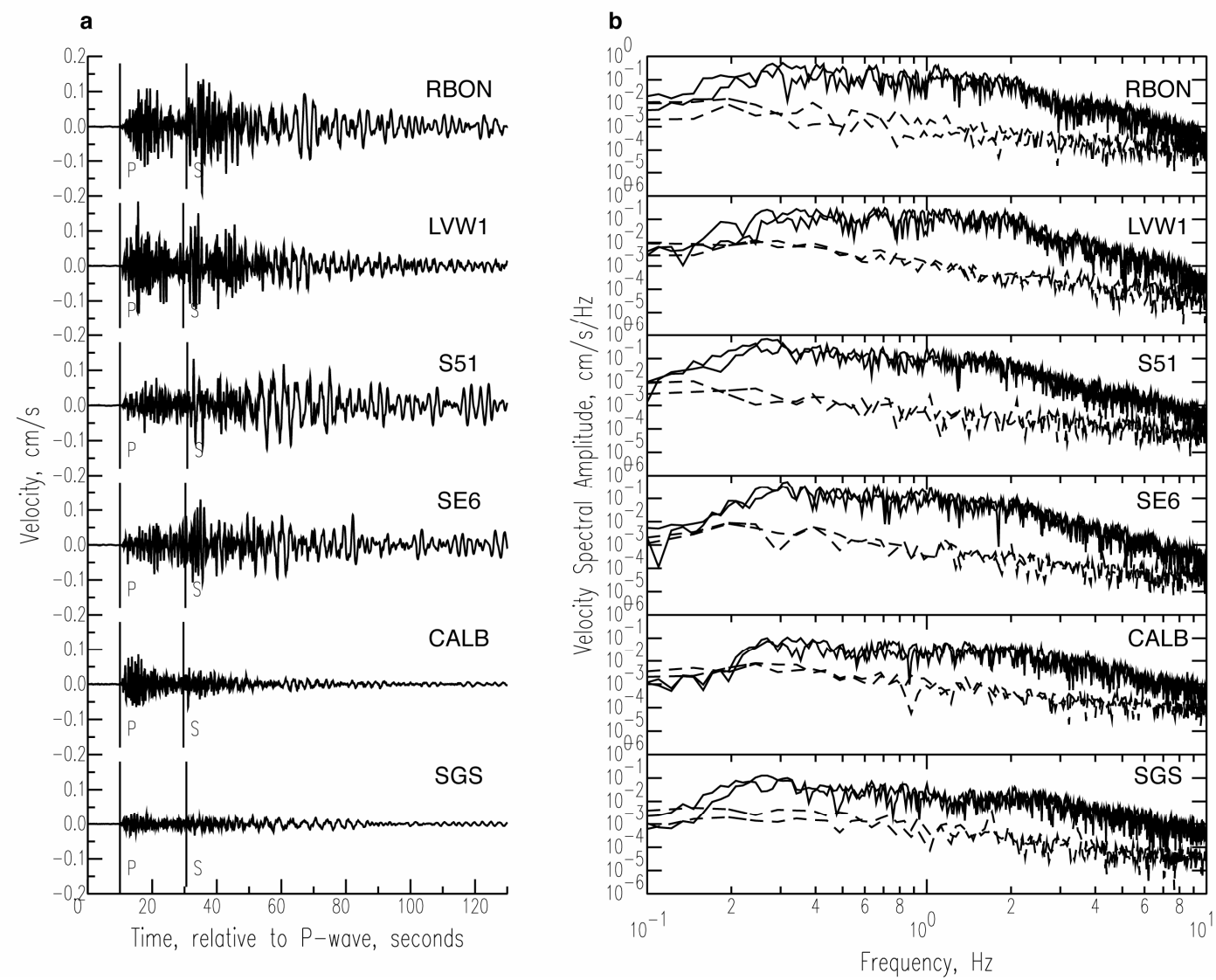

Figure 18. (a) North component velocity waveforms (filtered $0.1-10 \mathrm{~Hz}$ ) for the BARNWELL nuclear test at a few sites in LVV. (b) Horizontal component velocity amplitude (solid) and noise (dashed) spectra for the waveforms shown in (a). 
Figure $18 \mathrm{~b}$ shows the velocity amplitude spectra $(0.1-10 \mathrm{~Hz})$ of the S-wave and available pre-event noise windows for both horizontal components at the same sites as Figure 18a. Signal-to-noise ratios are quite high, generally greater than 10 , for all shots and sites in the band 0.2-10 Hz. The BLUME accelerographs were band-limited at the low end between 0.1 and $0.2 \mathrm{~Hz}$. The velocity spectra on both horizontal components have similar amplitudes. The peak amplitude occurs at around 0.2-0.4 Hz (2.5-5 s) for these stations. Data from other explosions had lower signal-to-noise ratios, either because were smaller or the sites were noisier.

\section{Acknowledgements}

This work performed under the auspices of the U.S. Department of Energy by Lawrence Livermore National Laboratory under Contract DE-AC52-07NA27344. This is LLNL contribution LLNL-TR-??????.

\section{References}

Davis, L. and R. Lynch (1970). Seismic response characteristics at Las Vegas, Nevada, from underground nuclear detonations, NVO-1163-203, Environmental Research Corporation.

Goldstein, P., D. Dodge, M. Firpo and L. Miner (2003). SAC2000: Signal processing and analysis tools for seismologists and engineers, in International Handbook of Earthquake and Engineering Seismology, Vol. 81B, International Association of Seismology and Physics of the Earth's Interior, 1613-1614.

Langenheim, V., J. Grow, R. Jachens, G. Dixon, and J. Miller (2001). Geophysical constraints on the location and geometry of the Las Vegas Valley Shear Zone, Nevada, Tectonics, 20, 189-209.

Mayeda, K., and W. Walter (1996). Moment, energy, stress drop and source spectra of western United States earthquakes form regional coda envelopes, J. Geophys. Res., 101, 11,195-11,208.

Murphy, J. and R. Hewlett (1975). Analysis of seismic response in the city of Las Vegas, Nevada: A preliminary microzonation, Bull. Seism. Soc. Am., 65, 1575-1597.

Rodgers, A., H. Tkalcic, D. McCallen, S. Larsen and C. Snelson (2006). Site response in Las Vegas Valley, Nevada from NTS explosions and earthquake data, Pure appl. Geophys, 163, 55-80. 
Rodgers, A., H. Tkalcic and D. McCallen (2005). The Las Vegas Valley Seismic Response Project: Ground motions in Las Vegas Valley from nuclear explosions at the Nevada Test Site, technical report, UCRL-TR-210758, Lawrence Livermore National Laboratory.

Su, F., J. Anderson, S. Ni and Y. Zeng (1998). Effect of site amplification and basin response on strong motion in Las Vegas, Nevada, Earthquake Spectra, 14, 357-376. 